\title{
A biblioteca universitária na educação a distância: papel, características e desafios
}

\section{Priscila Machado Borges Sena}

\begin{abstract}
Professora Substituta no Departamento de Ciência da Informação da Universidade Federal de Santa Catarina.Mestrado em Ciência da Informação pela Universidade Federal de Santa Catarina/Florianópolis. Especialização em Gestão do Conhecimento pela Faculdade Integrada da Grande Fortaleza.Graduação em Biblioteconomia pela Universidade Federal de Mato Grosso/Rondonópolis
\end{abstract}

Magda Teixeira Chagas

Professora Associada da Universidade Federal de Santa Catarina.Doutorado em Linguística pela Universidade Federal de Santa Catarina .Mestrado em Bibliotecas Públicas, pela Universidade Federal da Paraíba .Graduação em Biblioteconomia e Documentação pela Universidade Federal do Rio Grande do Sul

http://dx.doi.org/10.1590/1981-5344/2518

A Educação a Distância atrai adeptos que buscam flexibilidade para atender à complexidade de fenômenos proporcionados pela sociedade da informação. A presença das bibliotecas nos polos presenciais, é considerada primordial por representar a extensão das bibliotecas universitárias. Sabendo das dificuldades pelas quais passam as diferentes bibliotecas em nosso país, surge a preocupação sobre como estão sendo gerenciadas e mantidas essas instituições nos polos presenciais do Estado de Santa Catarina. O objetivo geral desta pesquisa é diagnosticar a situação atual das bibliotecas universitárias existentes nos polos de EaD, localizados no Estado de Santa Catarina, que ofertam cursos de graduação da Universidade Federal de Santa Catarina. Quanto aos procedimentos metodológicos, a pesquisa classifica-se como exploratória-descritiva, utiliza o método de levantamento e apresenta uma abordagem qualiquantitativa. Constata-se que papel da Biblioteca Universitária na EaD é o de contribuir para a satisfação das necessidades informacionais de professores, alunos, técnicos e comunidades nas quais estão inseridas, 
fornecendo acesso às distintas fontes de informação. Ressalta-se que a presença de bibliotecários contribuiria para uma série de melhorias a serem implementadas nas bibliotecas analisadas. Percebe-se a necessidade da construção de parâmetros de qualidade que contribuam para a estruturação das bibliotecas dos polos de apoio presencial.

Palavras-chave: Biblioteca universitária. Educação a distância. Polo presencial. Universidade Federal de Santa Catarina.

\section{The university library in distance education: paper, features and challenges}

Distance Education attracts people who are dependent on the knowledges present in the environment they live in but are, however, searching for flexibility to understand the complexity of the phenomena caused by the information society. The presence of libraries in classroom poles, on which it performs the university education of many students is considered paramount by represent the extent of university libraries. Knowing the difficulties different libraries in our country undergo, worry about how these institutions are being managed and maintained in classroom poles in the State of Santa Catarina arises. The overall objective of this research is to diagnose the current situation of university libraries existing in centers of Distance Education, in the State of Santa Catarina, that offer graduate courses of the Universidade Federal de Santa Catarina. As for the methodological procedures, the research is classified as exploratory and descriptive, using the survey method and presents a quali-quantitative approach. It appears that the role of the University Library in Distance Education is to contribute to meeting the informational needs of teachers, students, technicians and communities in which they operate, providing access to different sources of information. Surely the presence of these professionals would contribute to a number of improvements to be implemented in such libraries. It is realized the need to build quality parameters that contribute to the structuring of the libraries of the support classroom poles. 
Keywords: University libraries. Distance education. Classroom poles. Federal University of Santa Catarina.

Recebido em23.08.2015 Aceito em 11.11.2015

\section{Introdução}

O advento das tecnologias de informação e comunicação (TIC) trouxe consigo a possibilidade de ampliar a formação de indivíduos que, por não residirem nos grandes centros ou por não disporem de tempo suficiente para frequentar cursos regulares nas universidades, mantinham-se privados das possibilidades de formação profissional continuada e competente. Com as TIC, ampliaram-se as possibilidades de criação e manutenção de cursos a distância, que garantem aos indivíduos o acesso ao conhecimento, mesmo distantes das diferentes faculdades e universidades.

Nesse sentido, a educação a distância (EaD) tem como objetivo transmitir e/ou construir conhecimento sem a presença física e simultânea dos sujeitos envolvidos (NOVA; ALVES, 2003). Dessa forma, a EaD atrai adeptos que buscam flexibilidade para atender à complexidade de fenômenos proporcionados pela sociedade da informação. Com uma longa história de atuação no Brasil, que se iniciou ainda no século XVIII, a EaD ganhou maior popularidade no século $\mathrm{XX}$, mais precisamente a partir da década de 90. Nesse período, ocorreu uma mobilização das Instituições de Ensino Superior (IES), auxiliadas pelas, até então, novas TIC que impulsionaram a educação a distância, com a criação de cursos de formação de professores e em diversas áreas de qualificação (ALVES, 2011; ARAÚJO; FREITAS, 2005).

Com a criação do Sistema Universidade Aberta do Brasil (UAB), no ano de 2005, no âmbito do Fórum das Estatais pela Educação, emergiu a proposta de expansão e interiorização da oferta de cursos e programas de educação superior para todo o país. Em 2006, o Decreto 5.773 de 9 de maio de 2006 (BRASIL. Presidência da República, 2006), regulamentou critérios físicos, tecnológicos e didáticos, que visavam à qualidade dos cursos oferecidos. Entre os recursos exigidos através desse documento encontram-se: acesso à Internet, bibliotecas, laboratórios e professores de apoio. Quanto às bibliotecas, essas devem possuir:

[...] acervo de livros, periódicos acadêmicos e científicos e assinaturas de revistas e jornais, obras clássicas, dicionários e enciclopédias, formas de atualização e expansão, identificado sua correlação pedagógica com os cursos e programas previstos; vídeos, DVD, CD, CD-ROMS e assinaturas eletrônicas; espaço físico para estudos e horário de funcionamento, pessoal técnico administrativo e serviços oferecidos (BRASIL. Presidência da República, 2006). 
Ainda em 2006, a UAB foi oficializada pelo Decreto 5.800 de 8 de junho de 2006. Em 2007, o Ministério da Educação e Cultura (MEC) por meio da Portaria Normativa 2, de 10 de janeiro de 2007, artigo 2, inciso 3, determinou que para requerer a ampliação da abrangência de atuação, a UAB deveria aumentar o número de polos presenciais (BRASIL. Ministério da Educação e Cultura, 2007, p. 2). Os polos passaram a funcionar como extensões das universidades, sendo instalados em municípios e atuando como importante ponto de apoio para os estudantes. A instalação dos polos de apoio foi essencial para a solidificação dos cursos a distância, podendo os cursos, a partir deles, serem considerados semipresenciais.

Nesse contexto, as bibliotecas universitárias são consideradas essenciais para a formação acadêmica e profissional, tendo como papel principal promover acesso às informações e estimular a construção conhecimento. Sua presença nos polos presenciais, nos quais se realiza a formação universitária de estudantes é, portanto, considerada primordial. Essas instituições devem servir como elemento de apoio aos cursos ofertados, contando com acervo atualizado, abrangente e compatível com os conteúdos ensinados, em diferentes mídias.

Sabendo das dificuldades pelas quais passam as diferentes bibliotecas em nosso país, surge a preocupação sobre como estão sendo gerenciadas e mantidas essas instituições nos polos presenciais do Estado de Santa Catarina. A partir dessa preocupação, estabelece-se a seguinte questão a ser respondida: as bibliotecas dos polos presenciais estão sendo planejadas, implantadas e mantidas com as características de uma biblioteca universitária, capaz de atender aos diferentes cursos superiores existentes nos polos, estando aí incluídos um acervo de qualidade, pessoal técnico competente e serviços ao público adequados às necessidades dos estudantes?

Esse questionamento está diretamente ligado à relevância que assumem os cursos a distância para a formação de grande número de estudantes. Esses se encontram distantes dos grandes centros nos quais estão instaladas a maioria das universidades e que buscam na EaD a oportunidade de se formar e qualificar, contribuindo para a construção de uma sociedade melhor e mais qualificada. Busca-se, assim, conhecer mais a respeito das bibliotecas dos polos presenciais de $\mathrm{EaD}$, identificando seu papel, características e desafios.

A Universidade Federal de Santa Catarina (UFSC) foi uma das pioneiras na implantação de cursos a distância, ofertando cursos em nível de graduação e pós-graduação, em diversas regiões do país, contribuindo para a formação de centenas de estudantes, de diferentes localidades. Esse fato contribuiu para a construção dos objetivos desta pesquisa, tanto geral como específicos, descritos a seguir.

Como Objetivo geral, determinou-se: diagnosticar a situação atual das bibliotecas universitárias existentes nos polos de EaD, localizados no Estado de Santa Catarina, que ofertam cursos de graduação da 
Universidade Federal de Santa Catarina. Para o seu cumprimento, objetivou-se, especificamente: a) Identificar os polos de EaD do Estado de Santa Catarina que ofertam cursos de graduação da UFSC; b)caracterizar os recursos humanos alocados nas bibliotecas quanto ao número de funcionários, formação, situação funcional e participação em educação continuada; c) identificar as características físicas das bibliotecas e a composição e características de seu acervo; d) identificar os produtos e serviços ofertados nas bibliotecas, seu horário de funcionamento e especificidades relativas ao processo de inclusão e acessibilidade; e) caracterizar os usuários das bibliotecas e suas necessidades, bem como os recursos utilizados para a comunicação com os mesmos.

A motivação para a realização desta pesquisa baseou-se na propagação da Educação a Distância, somada à expansão das TIC e à necessidade de comprovar que as bibliotecas universitárias e suas extensões em polos de EaD contribuem ou podem contribuir de maneira significativa para a qualidade do ensino ali ofertado. Algumas pesquisas realizadas nos últimos anos instigaram o interesse no tema e apontam problemas referentes à falta de bibliotecários nas bibliotecas dos polos de apoio presencial de ensino e às falhas nos serviços ofertados aos alunos dos cursos semipresenciais (SEMABAY, 2009; MATTOS FILHA; CIANCONI, 2010; MATTOS FILHA, 2013).

Para atender os objetivos propostos realizou-se uma pesquisa exploratória-descritiva, utilizando uma abordagem mista e o método de levantamento. O universo desta pesquisa foi constituído pelas bibliotecas existentes nos Polos de EaD de Santa Catarina que oferecem cursos de graduação da UFSC e são gerenciados pela UAB/MEC. Assim, a amostra se estabeleceu em 21 polos ofertantes dos cursos de graduação da UFSC, todos possuindo bibliotecas.

Como fonte de pesquisa utilizou-se o sistema de busca do Portal CAPES (http://www.uab.capes.gov.br). Os dados foram coletados de 5 nov. 2013 a 17 dez. 2013.

\section{Bibliotecas universitárias e EaD}

As bibliotecas universitárias durante a sua trajetória nunca foram autônomas na realização de suas atividades, por se tratarem de "[...] organizações dependentes de uma organização maior - a Universidade, portanto sujeitas a receberem influências externas e internas do ambiente que as cerca" (MACIEL; MENDONÇA, 2000, p. 2). Uma biblioteca em uma universidade deve representar auxílio às atividades acadêmicas (SOUSA, 2009). Isso porque, de acordo com Antonio (2013), dentro de uma instituição de ensino superior, "desde sempre, a biblioteca universitária é vista como o 'coração da universidade'".

Para atender aos requisitos exigidos, as bibliotecas universitárias precisam se inovar constantemente, acompanhando as mudanças de seu público. Isso porque faz parte da sua missão promover o acesso e incentivar o uso e a geração da informação, em todas as áreas do conhecimento, com a utilização eficaz dos recursos públicos ou privados. 
Ramos (1996, p. 2) afirma que "o negócio das unidades de informação é, portanto, o de disseminar informações precisas e prestar correta assistência". Embora, historicamente as bibliotecas venham atuando na organização e preservação dos registros do conhecimento, "passaram a ter um papel mais incisivo na disseminação e promoção do acesso à informação." (FELÍCIO, 2014, p. 173).

$\mathrm{Na}$ modalidade de EaD, a existência de bibliotecas nos polos é um critério básico para que ocorra a sua consolidação, sendo um item a ser considerado quando do processo de avaliação estabelecido pelo MEC. Conforme documento que apresenta os Referenciais de Qualidade para a educação superior, desenvolvido por equipe do MEC, a biblioteca está citada junto aos elementos estruturais necessários para a consolidação dos cursos, tal como segue:

\section{Instalações Físicas}

a) infra-estrutura material que dá suporte tecnológico, científico e instrumental ao curso;

b) infra-estrutura material dos pólos de apoio presencial;

c) existência de biblioteca nos pólos, com um acervo mínimo para possibilitar acesso aos alunos a bibliografia, além do material instrucional utilizado pelo curso;

d) sistema de empréstimo de livros e periódicos ligado à sede da IES para possibilitar acesso à bibliografia mais completa, além do disponibilizado no pólo (BRASIL. Presidência da República, 2007, p. 2).

Em 2007, os Referenciais de Qualidade ficam estabelecidos através do Decreto n. 6.303, de 12 de dezembro de 2007, o qual determina que

$\S 70$ As instituições de educação superior integrantes dos sistemas estaduais que pretenderem oferecer cursos superiores a distância devem ser previamente credenciadas pelo sistema federal, informando os pólos de apoio presencial que integrarão sua estrutura, com a demonstração de suficiência da estrutura física, tecnológica e de recursos humanos. (NR). (BRASIL. Presidência da República, 2007).

Nesse contexto, as bibliotecas dos polos tornam-se uma extensão da Biblioteca Universitária. No entanto, é difícil sua concretização, uma vez que não possuem regulamentação quanto aos padrões físicos e de serviços.

Em resposta aos desafios dessa modalidade de ensino aprendizagem, ainda em 1990, a Association of College \& Research Libraries (ACRL), estabeleceu um conjunto de diretrizes para os serviços bibliotecários a serem oferecidos para alunos de cursos superiores a 
distância. E, em 1998, este documento foi atualizado, exigindo das bibliotecas dos polos:

Aumento no número de ambientes únicos onde as oportunidades educacionais são oferecidas; reconhecimento crescente da necessidade de recursos e serviços bibliotecários disponíveis em lugares outros que o campus universitário principal; preocupação em satisfazer demanda crescente e constante por serviços iguais para todos os estudantes de cursos superiores, independentemente de onde se localiza a "sala de aula"; aumento da demanda por recursos e serviços bibliotecários feita por professores e pessoal de apoio que se encontram nos locais de ensino afastados do campus; progresso nas inovações tecnológicas na transmissão de informação e dos cursos (ACRL, 1998' apud MUELLER, 2000, p. 5).

Pizzani et al. (2011) justificam a preocupação desse grupo, quando afirmam que a constante inovação tecnológica influencia as bibliotecas colaboradoras da educação a distância, no que diz respeito às facilidades de acesso às distintas fontes de informação, oferecidas aos seus usuários. Com o aumento dos cursos de educação a distância, somado ao uso das TIC pelos usuários, os bibliotecários universitários foram levados a repensar o papel da biblioteca universitária nesse modelo educacional.

Segundo Amante, Placer e Costa (2009) e Antonio (2013), o novo ambiente dinâmico impulsionado pelas TIC, explosão de conteúdos digitais e pelas facilidades oferecidas com uso da Internet suscitam transformações no ensino e na aprendizagem, na comunicação acadêmica e no papel tradicional dos serviços de informação.

Nesse contexto, o papel tradicional do bibliotecário que tem sido o de mediador entre o documento e o seu leitor, sofre profundas alterações. De acordo com Bueno e Blattmann (2005), o profissional da informação precisa conhecer os recursos informacionais disponíveis para ser capaz de pesquisar conteúdos e ser ético no uso da informação.

Araújo e Dias (2005) afirmam ser necessário ao bibliotecário um perfil pró-ativo que se antecipe à exigência do usuário. Podem utilizar recursos da educação a distância para realizar treinamentos síncronos e assíncronos. Essa nova forma de ensinar e aprender pode ser utilizada pelos bibliotecários também como forma de se reciclar e se aperfeiçoar nas técnicas de gerenciamento e controle das informações. As mudanças nos formatos, recursos e suportes das informações obrigam os bibliotecários a se manterem informados das novidades a fim de transmiti-las a seus usuários.

$\mathrm{Na}$ biblioteca universitária, é necessário estar atento constantemente para a real satisfação do usuário, que vai além do acesso

\footnotetext{
${ }^{1}$ ASSOCIATION OF COLLEGE AND RESEARCH LIBRARIES (ACRL). Guidelines for distance learning library services . [s.I.]: ALA/ACRL, 1998.
} 
aos serviços. Nesse sentido, o estudo de usuário torna-se uma importante ferramenta a ser utilizada pela biblioteca, visando conhecer as necessidades dos usuários e a percepção e satisfação desses. Entende-se que "não basta a disponibilização de livros e periódicos, bases de dados e equipamentos de última geração, é preciso que tais recursos sejam mobilizados a favor de seus usuários" (SOUSA, 2009, p. 12). É importante que a informação disponibilizada represente valor ao usuário, ou seja, a unidade de informação precisa identificar quais produtos são mais valorizados, procurando conhecer a necessidade informacional da sua clientela (SENA; TREVISOL NETO; VARVAKIS, 2013).

A possibilidade de interação com os elementos eletrônicos, trazida pela disseminação da Web 2.0, amplia as possibilidades de criação de serviços e produtos a serem disponibilizados aos usuários. No serviço de Referência, podem ser utilizados esses recursos para interagir com os usuários, respondendo suas questões informacionais de forma mais dinâmica e pontual. Para tanto, é necessário que o bibliotecário reveja suas práticas e desenvolva parcerias com outras bibliotecas e instituições congêneres, ampliando as possibilidades de acesso à informação disponibilizada aos usuários.

A biblioteca universitária da UFSC vem desenvolvendo um trabalho de qualidade, desde que foi criada, na década de 60, do século XX, para atender as demandas de uma universidade emergente. Como forma de participar e de contribuir com o processo de ensino-aprendizagem desenvolvido nos vários cursos oferecidos pela UFSC, oferecem-se, através do Portal da Biblioteca, diversos produtos e serviços, estando entre eles: a renovação e reserva de documentos, tutoriais para o uso de bases de dados, e-books, periódicos on-line, entre outros.

Todos os serviços colocados à disposição dos alunos presenciais são também colocados à disposição dos alunos a distância. No entanto, apesar de possuírem os mesmos direitos, os alunos dos cursos a distância, muitas vezes, não conseguem se deslocar para a capital, nem tampouco possuem Internet com boa velocidade para acessar os materiais digitais.

Dessa forma, as bibliotecas existentes nos polos presenciais de Santa Catarina são de grande importância no auxílio às atividades acadêmicas dos estudantes, professores, técnicos administrativos e comunidades em que estão inseridas.

\section{Resultados: apresentação e discussão}

A apresentação e discussão dos dados segue descrita de acordo com os objetivos estabelecidos para a pesquisa. Esta seção está amparada pelo cruzamento dos dados com a literatura utilizada. 


\subsection{Caracterização dos recursos humanos alocados nas bibliotecas quanto ao número de funcionários, formação, situação funcional e participação em educação continuada}

Quanto ao número de funcionários atuantes nas bibliotecas dos polos, percebeu-se que 16 (80\%) bibliotecas contam com somente um funcionário para atender aos diferentes horários de trabalho do polo. Em duas $(10 \%)$ bibliotecas, não existem funcionários especificamente responsáveis pelas mesmas, estando seu gerenciamento sob a responsabilidade do coordenador do polo. Em uma ( $5 \%)$ biblioteca atuam dois funcionários respectivamente e em outra (5\%), três funcionários, sendo esta a única biblioteca que possui um responsável graduado em Biblioteconomia. Esse fato é preocupante, considerando que os polos de educação a distância têm um horário de funcionamento bastante estendido, permanecendo abertos nos três turnos. O baixo número de funcionários atuantes nas bibliotecas, certamente dificulta a realização das atividades de atendimento aos usuários e de organização das coleções.

Com isso, perdem os usuários, uma vez que segundo Bueno e Blattmann (2005), Araújo e Dias (2005) e Sousa (2009), o bibliotecário tem responsabilidades no processo de disseminação de informações aos usuários, contribuindo em todo o processo de sua escolarização.

Em relação ao nível de escolaridade dos responsáveis pelas bibliotecas, os dados revelaram que oito (40\%) possuem pós-graduação completa; sete (35\%) possuem ensino superior completo; dois $(10 \%)$ possuem ensino superior incompleto; dois (10\%) possuem ensino médio completo e um ( $5 \%$ ) possui pós-graduação incompleta. Pode-se afirmar que, apesar de não possuírem graduação em Biblioteconomia, na maioria das bibliotecas os responsáveis têm formação adequada para o atendimento ao público, uma vez que $80 \%$ deles possui formação superior ou maior.

Para aqueles que informaram que os responsáveis não possuíam formação em Biblioteconomia, foi solicitado que informassem suas escolarizações. Os dados demonstraram que somente um $(5 \%)$ funcionário tem formação em Biblioteconomia, contrariando o que está estabelecido no decreto 5.773, de 9 de maio 2006, que afirma ser necessário que as bibliotecas possuam regime de funcionamento e atendimento adequados aos estudantes (BRASIL. Presidência da República, 2006). Entende-se que para minimamente suprir tal requisito deveria haver pelo menos um funcionário com formação em Biblioteconomia, pois este profissional possui capacidade e formação adequada para o gerenciamento das bibliotecas e para o atendimento as necessidades informacionais dos usuários.

Ainda quanto aos responsáveis, oito (40\%) possuem formação em Pedagogia. Os demais variam em diferentes áreas de formação, destacando-se as licenciaturas. Um (5\%) dos responsáveis pelas 
bibliotecas possui especialização em Gestão de Bibliotecas Escolares, minimizando a falta de conhecimento na área de atuação. Diante dessa realidade, seria interessante que esses responsáveis tivessem no mínimo uma espacialização voltada para a gestão das bibliotecas, suprindo parcialmente a ausência do bibliotecário!

Quanto ao vínculo empregatício dos responsáveis pelas bibliotecas, 13 deles (65\%) afirmaram ser concursados na Prefeitura do município em que está localizado o polo; três (15\%) são contratados pela Prefeitura; dois $(10 \%)$ seguem o regime da Consolidação das Leis do Trabalho (CLT); e dois (10\%) são estagiários. Por meio desses dados, infere-se que há 13 polos que possuem funcionários concursados. O ideal é que esses fossem bibliotecários e não profissionais de outras áreas, sem capacidade técnica específica para o gerenciamento de uma biblioteca.

Considerando a importância de se ter uma formação continuada que permita aos funcionários atuar de forma mais competente em suas funções, os responsáveis pelas bibliotecas foram questionados quanto à participação em cursos de formação continuada. Dos 20 entrevistados, 14 (70\%) responderam não ter participado de cursos de formação continuada e seis (30\%) afirmaram que participam de cursos de formação. Ou seja, atuam de forma improvisada no gerenciamento das bibliotecas. Percebese aqui uma certa negligência quanto à necessidade dos conhecimentos específicos para a administração das bibliotecas, tornando-as apenas espaços para guarda de documentos. Tal como sugerem Araújo e Dias (2005), os bibliotecários universitários poderiam utilizar os recursos oferecidos pela EaD para treinarem os profissionais atuantes nas bibliotecas dos polos, auxiliando-os em sua atuação.

\subsection{Identificação das características físicas das bibliotecas e a composição e características de seu acervo}

Quanto à propriedade da biblioteca, 12 (60\%) são de propriedade dos polos; seis (30\%) são compartilhadas com uma escola; duas $(10 \%)$ apresentam outros tipos de compartilhamento, sendo uma compartilhada com o município e outra com a comunidade. Mais um dado que reforça a necessidade de bibliotecários.

Com relação às áreas existentes nas bibliotecas, $16(80 \%)$ possuem Área de leitura, estudo e pesquisa; 15 (75\%) de atendimento ao público; 13 (65\%) de armazenamento de acervo; 5 (25\%) de estudos individuais. Em duas (10\%) bibliotecas foi utilizada a opção Outros, sendo indicado que possuem Acesso à Internet e Área toda aberta (livros e espaços para estudo). Quando somadas as porcentagens, nota-se que ultrapassam os $100 \%$, isso porque essa questão era de múltipla escolha.

A partir desses dados, percebe-se que os espaços mais presentes nas bibliotecas foram a área de atendimento ao público e a área de leitura, estudo e pesquisa. Somente em 13 (65\%) bibliotecas foi indicado que existe espaço para armazenamento do acervo. Esse dado é 
preocupante, considerando que todos os cursos enviam livros para os polos para que sejam utilizados pelos alunos. Não havendo espaço para o acervo, de que forma esses livros são disponibilizados a professores e alunos? Para responder a essa pergunta seria necessária uma visita ao local, para perceber a organização ali implantada, fato que, no entanto, não foi objetivo dessa pesquisa.

Em relação aos tipos e quantidade de acervo existente nas bibliotecas: Livros, Periódicos, Bases de Dados, DVDs e outros, percebese, que os documentos que estão presentes em todos os polos são os livros impressos. Esse fato é compreendido, considerando que todos os cursos a distância recebem verba do MEC para a compra desse material, para dar suporte às atividades de ensino-aprendizagem por eles desenvolvidos. A quantidade de títulos disponíveis variou de 100 a (P14) e 9.340 (P9); os exemplares variaram de 315 (P16) a 15.618 (P9).

Os dados revelaram ainda que 12 (60\%) bibliotecas possuem periódicos, variando a indicação do número de títulos de três a 500 . Somente em dois polos foi indicada a presença de Bases de Dados assinadas, sendo os dados indicados bastante altos. Certamente, esses dados se referem às bases de dados disponibilizadas pela Biblioteca Universitária da UFSC, a qual os alunos têm acesso, ao se matricularem nos cursos. No entanto, mais uma vez, percebem-se os problemas advindos da ausência de bibliotecários nos polos, que poderiam auxiliar os alunos no uso desses recursos para suas atividades de aprendizagem.

Os DVDs estão também presentes em grande número nos acervos das bibliotecas dos polos. Isso se deve ao fato de ser este um documento bastante utilizado nos cursos a distância para auxiliar na compreensão dos tópicos trabalhados em cada disciplina ou módulo. A quantidade de títulos por polo variou entre 12 (P20) e 681 (P6) e a dos exemplares entre 20 (P20) e 681 (P6), sendo que seis (30\%) polos não possuem DVDs. Quanto à existência de outros tipos e quantidades de documentos, apenas em um polo (5\%) (P2) afirmou-se possuir 25 monografias.

Quanto à forma de solicitação, a maior parte 15 (75\%), nunca solicitou compra de documentos, três (15\%) realizaram solicitação por intermédio dos professores, duas (10\%) realizaram solicitação por e email, uma (5\%) realizou solicitação junto à Biblioteca. Esses dados revelam que mesmo tendo, desde 2011, a liberdade para a solicitação de materiais, em 15 (75\%) bibliotecas nunca foi realizada a solicitação de materiais.

Em relação a existência e forma de incentivo por parte dos professores ao uso dos produtos e serviços, percebeu-se que em 18 $(90 \%)$ polos, os professores incentivam o uso da biblioteca; em dois (10\%) os professores não incentivam. Dentre os $18(90 \%)$ em que os professores incentivam o uso da biblioteca, nove (45\%) incentivam por meio de indicação de bibliografias, citando autores, separando livros e sugerindo leituras, quatro (20\%) incentivam por intermédio de pesquisas e trabalhos, dois (10\%) pela divulgação do acervo e outros dois $(10 \%)$ por meio da promoção de grupos de estudo e pesquisa, um (5\%) por meio de atividades pedagógicas. 


\subsection{Identificação dos produtos e serviços ofertados nas bibliotecas, seu horário de funcionamento e especificidades relativas ao processo de inclusão e acessibilidade.}

Quanto aos horários de funcionamento das bibliotecas, estes corresponderam a $12(60 \%)$ bibliotecas que funcionavam em períodos vespertino e noturno; oito (40\%) que funcionavam em período integral. Vale registrar que, das 20 bibliotecas, cinco (25\%) apresentaram funcionamento em períodos diferenciados nos sábados; uma $(5 \%)$ durante a semana. Os períodos diferenciados referem-se às bibliotecas dos polos que apresentam diferentes períodos de trabalho. Nota-se por esses dados, que em apenas oito (40\%) bibliotecas consegue-se atender os usuários em todos os períodos. As demais deixam vago o período matutino, verificando-se uma falta de preocupação com aqueles que trabalham em período vespertino e noturno, possuindo tempo livre apenas na parte da manhã. Essa falta de atendimento no período matutino poderia ser suprida no final de semana, no entanto, de acordo com os dados expostos, apenas cinco (25\%) bibliotecas abrem aos sábados. Quando somadas as porcentagens, nota-se que ultrapassam os $100 \%$, isso porque essa questão era de múltipla escolha.

A partir dos dados apresentados, observa-se que em 13 (65\%) bibliotecas oferta-se o Portal $B U$; em dez (50\%), ofertam-se materiais impressos; em quatro (20\%) oferta-se o BU Informa e em três (15\%) a Web TV. Esses índices são muito baixos, considerando que esses serviços oferecidos pela Biblioteca Universitária da UFSC estão disponíveis em seu site, fato que facilita seu uso por toda a comunidade universitária. Por se tratar de um questão de múltipla escolha, quando somadas as porcentagens, nota-se que ultrapassam os $100 \%$.

Quanto à Disseminação Seletiva da Informação (DSI), nenhum polo possui biblioteca que ofereça esse serviço. Esse dado revela que um serviço de grande potencial e benéfico para toda a comunidade usuária do polo, principalmente aos professores e funcionários não tem sido explorado. Mais uma vez, esse fato pode ser atribuído à ausência de profissionais capacitados para realizar esse serviço, que, com certeza, agregaria valor à existência da biblioteca.

Com relação ao serviço de consulta e empréstimo, 16 (80\%) bibliotecas o possuem e quatro (20\%) não possuem. O fato de existirem cinco bibliotecas que, embora possuam acervo, não o disponibilizem aos usuários é bastante preocupante. Segundo Sousa (2009), a missão de uma biblioteca é a de auxiliar nas atividades acadêmicas. Esse auxílio, no entanto, não vem se concretizando.

Quanto a possuir acervo que atenda as necessidades especiais, infelizmente os dados demonstram que 18 (90\%) bibliotecas não o possuem e apenas duas (10\%) possuem-no, contrariando a Lei 4.169 de 4 de dezembro de 1962 que determinou a obrigatoriedade e oficializou as convenções Braille, para uso na escrita e leitura dos cegos. 
Quando investigadas se seguem as normas de acessibilidade, em onze (55\%) bibliotecas indicou-se não seguir e em nove (45\%), indicouse seguir. Esse é outro dado preocupante, considerando que todas as pessoas têm o direito de ir e vir e, de acordo com a Lei 10.098, art. 20, inc. I, a acessibilidade é entendida como:

[...] possibilidade e condição de alcance para utilização, com segurança e autonomia, dos espaços, mobiliários e equipamentos urbanos, das edificações, dos transportes e dos sistemas e meios de comunicação, por pessoa portadora de deficiência ou com mobilidade reduzida (BRASIL. Presidência da República, 2000).

\subsection{Caracterização dos usuários das bibliotecas e suas necessidades, bem como os recursos utilizados para a comunicação com os mesmos}

Quanto à realização de estudo de usuário, em 19 (95\%) bibliotecas não se realizam e apenas em uma (5\%), realiza-se. A explicação quanto a não existência de acervo que atenda a necessidades especiais, na maior parte das bibliotecas, provavelmente esteja ligada a este ponto. Considera-se o estudo de usuário importante ferramenta que visa "coletar dados para criar e ou avaliar produtos e serviços informacionais, bem como entender melhor 0 fluxo da transferência da informação" (BAPTISTA; CUNHA, 2007, p. 169). Dessa forma, ele contribui também para as características dos usuários da biblioteca, identificando se remotos ou presenciais, ou ambos os tipos.

No caso das bibliotecas pesquisadas, mesmo sem estudo de usuários a indicação foi de que 20 (100\%) bibliotecas possuem como usuários alunos, 17 (85\%) professores, 14 (70\%) funcionários e sete (35\%) a comunidade onde a biblioteca está inserida. Porém, com o estudo de usuários, esses dados poderiam ser determinados com maior confiabilidade. Quando somadas as porcentagens, nota-se que ultrapassam os $100 \%$, isso porque essa questão era de múltipla escolha.

Quanto aos tipos de usuários, onze (55\%) responderam que seus usuários são remotos e presenciais, oito (40\%) que são presenciais, e um (5\%) remoto. Esses dados complementam aqueles que indicam o baixo uso dos recursos eletrônicos oferecidos pela Biblioteca Universitária da UFSC, comprovando haver uma falta de cuidado no atendimento aos usuários e suas necessidades.

Quanto ao número de usuários que costumam frequentar as bibliotecas, sete (35\%) respondentes afirmaram que são entre 5 e 10 , quatro (20\%) entre 3 e 4 , quatro (20\%) entre 11 e 20, três (15\%) entre 21 e 30 e duas (10\%) responderam imprecisamente. Esses índices são baixos e parecem estar de acordo com os espaços pequenos reservados às bibliotecas nos polos. Provavelmente, se houvesse maior cuidado na disponibilização de condições adequadas de estudo nas bibliotecas, essas recebessem maior número de usuários por dia. 
Com relação aos recursos utilizados para a comunicação com os usuários, em dezoito (90\%) bibliotecas utiliza-se o telefone, em 15 (75\%) utilizam e-mail e quatro (20\%) utilizam redes sociais. Essa questão também permitiu as múltiplas respostas. Parece ser ainda o telefone a forma mais direta de comunicação entre os responsáveis pela biblioteca e seus usuários, apesar da existência de outros meios também eficientes para este fim. Por se tratar de um questão de múltipla escolha, quando somadas as porcentagens, nota-se que ultrapassam os $100 \%$.

Dentre os cinco polos que deram opinião, o polo P16 expôs a dificuldade de contratação de um novo funcionário capacitado para o trabalho. O polo P6 registrou que não considera as bibliotecas dos polos universitárias, mesmo estas estando ligadas à Biblioteca Universitária da UFSC. Os outros três polos, P4, P8 e P19, respondentes desta questão, parabenizaram e destacaram a importância do diagnóstico realizado na pesquisa. Apesar de ter sido baixo o retorno a essa questão, as contribuições recebidas foram válidas para o reconhecimento do trabalho aqui realizado.

\section{Considerações finais}

As Considerações Finais estão substanciadas pelas constatações advindas da realização da pesquisa. Assim, a realidade observada nas bibliotecas analisadas não está condizente com àquela exigida de uma biblioteca universitária tradicional. Mesmo sendo uma extensão desse tipo de biblioteca, o modelo adotado nos polos presenciais analisados, não apresenta características adequadas ao trabalho desenvolvido na educação a distância. O modelo adotado nos polos lembra mais o de um depósito de materiais produzidos pelos cursos, sendo insignificante 0 trabalho de disseminação de informações ali desenvolvido.

Percebe-se que o bibliotecário para atuar nas bibliotecas de polos presenciais precisará estar apto a utilizar de forma dinâmica as TIC, retirando delas recursos adequados para suprir as necessidades informacionais de professores, alunos e demais envolvidos com o processo de ensino-aprendizagem a distância.

O modelo tradicional de biblioteca guardadora e disseminadora de materiais impressos não consegue atender as demandas exigidas por essa modalidade de ensino. Surge, assim, a necessidade de discussões mais aprofundadas no sentido de construir uma biblioteca que responda aos anseios informacionais, sem a necessidade da presença física do usuário no polo.

Os resultados demonstraram que as bibliotecas estão basicamente compostas por materiais impressos e DVDs produzidos pelos professores e equipe de apoio, responsáveis pelos diferentes cursos. Surge assim a necessidade de que se amplie esse acervo, disponibilizando material eletrônico, bem como outros suportes que contribuam para a transmissão de informações e conhecimento. Destaca-se a necessidade de que haja uma maior integração entre os responsáveis pelas bibliotecas e professores, na composição de bibliografia adequada a cada curso especificamente. 
Contudo, percebeu-se a necessidade da construção de parâmetros de qualidade que contribuam para a estruturação das bibliotecas dos polos de apoio presencial. Cabe destacar o bibliotecário como profissional capaz de pensar ações que possam transformar a realidade encontrada nessas bibliotecas, contribuindo de forma efetiva para a consolidação da EaD, no Estado de Santa Catarina e no restante do país.

Espera-se que este estudo provoque discussão e reflexão a respeito da realidade encontrada, destaca-se que a existência das bibliotecas exige investimentos, tanto de infraestrutura como de pessoal. Nota-se a necessidade de acervo adequado e de qualidade, ambiente condizente, profissionais habilitados e acima de tudo usuários que encontrem na biblioteca subsídios para o desenvolvimento de suas atividades educativas e de pesquisa. No entanto, a falta de permanência dos cursos nos polos estudados pode ser encarado como um empecilho para a efetivação da bibliotecas de apoio presencial e a possível contratação de bibliotecários!

\section{Referências}

ALVES, L. Educação a distância: conceitos e história no Brasil e no mundo. $R B A A D$, v. 10, p. 84-92, 2011. Disponível em: <http://www.abed.org.br/revistacientifica/Revista PDF Doc/2011/Artigo 07.pdf > .

Acesso em: 25 fev. 2013.

AMANTE, M. J.; PLACER, A. I. E.; COSTA, A. F. As bibliotecas universitárias na sociedade do conhecimento: o imperativo

da colaboração. Lisboa: Instituto Universitário de Lisboa; Repositório do ISCTE-IUL, 2009. Disponível em: $<$ http://www.egov.ufsc.br/portal/conteudo/bibliotecas-universit\%C3\%A1rias-nasociedade-do-conhecimento-o-imperativo-da-colabora\%C3\%A7\%C3\%A30>. Acesso em: 13 set. 2013.

ANTONIO, A. D. A biblioteca universitária no contexto da educação a distância. In: CONGRESSO BRASILEIRO DE BIBLIOTECONOMIA, DOCUMENTAÇÃO E CIÊNCIA DA INFORMAÇÃO, 25., 2013. Florianópolis, Santa Catarina, CBBD 2013. Anais... 2013. Disponível: <http://portal.febab.org.br/anais/article/view/1363>. Acesso em: 12 set. 2013.

ARAÚJO, B.; FREITAS, K. S. (Coord.). Educação a distância no contexto brasileiro: algumas experiências da UFBA. Salvador: ISP/UFBA, 2005. 170p. Disponível em: <http://www.proged.ufba.br/ead/EADnaUFBA.pdf $>$. Acesso em: 1 abr. 2013.

ARAÚJO, E. A.; DIAS, G. A. A atuação profissional do bibliotecário no contexto da sociedade da informação. In: OLIVEIRA, M. de. (Coord.). Ciência da informação e biblioteconomia: novos conteúdos e espaço de atuação. Belo Horizonte: Editora UFMG, 2005. p. 111-122.

BAPTISTA, S.; CUNHA, M. B. Estudo de usuários: visão global dos métodos de coleta de dados. Perspectivas em Ciência da Informação, v. 
12, n. 2, p. 168-184, maio/ago. 2007. Disponível em: <http://www.scielo.br/pdf/pci/v12n2/v12n2a11.pdf>. Acesso em: 25 fev. 2013.

BRASIL. Presidência da República. Decreto 5.773 de 9 de maio de 2006. Dispõe sobre o exercício das funções de regulação, supervisão e avaliação de instituições de educação superior e cursos superiores de graduação e sequenciais no sistema federal de ensino. Diário Oficial [da] República Federativa do Brasil, Brasília, DF, 10 maio 2006. Disponível em: $<$ http://www.planalto.gov.br/ccivil 03/ ato2004-2006/2006/decreto/d5773.htm > .

Acesso em: 25 fev. 2013.

BRASIL. Presidência da República. Decreto 5.800 de 8 de junho de 2006. Dispõe sobre o Sistema Universidade Abeta do Brasil - UAB. Diário Oficial [da] República Federativa do Brasil, Brasília, DF, 8 jun. 2006. Disponível em: $<$ http://www.planalto.gov.br/ccivil 03/ ato20042006/2006/decreto/d5800.htm >. Acesso em: 25 fev. 2013.

BRASIL. Ministério da Educação e Cultura. Secretaria de Educação à Distância. Referenciais de qualidade para educação superior à distância: versão preliminar. Brasília, DF: MEC, 2007. Disponível em: $<$ http://portal.mec.gov.br/seed/arquivos/pdf/legislacao/refead1.pdf $>$. Acesso em: 25 fev. 2013.

BRASIL. Ministério da Educação e Cultura. Portaria No 2, de 10 de janeiro de 2007. Dispõe sobre os procedimentos de regulação e avaliação da educação superior na modalidade a distância. Diário Oficial [da] República Federativa do Brasil, Brasília, DF, 11 jan. 2007. Disponível em: <http://portal.mec.gov.br/seed/arquivos/pdf/legislacao/portaria2.pdf >. Acesso em: 25 fev 2013.

BRASIL. Presidência da República. Decreto 6.303 de 12 de dezembro de 2007. Altera dispositivos dos Decretos $\mathrm{n}^{\mathrm{os}} 5.622$, de 19 de dezembro de 2005, que estabelece as diretrizes e bases da educação nacional, e 5.773, de 9 de maio de 2006, que dispõe sobre o exercício das funções de regulação, supervisão e avaliação de instituições de educação superior e cursos superiores de graduação e seqüenciais no sistema federal de ensino. Diário Oficial [da] República Federativa do Brasil, Brasília, DF, 12 dez. 2007. Disponível em: <http://www.planalto.gov.br/ccivil 03/ Ato20072010/2007/decreto/D6303.htm>. Acesso em: 25 fev 2013.

BUENO, S. B.; BLATTMANN, Ú. Fontes de informação on-line no contexto da área de Ciências da Saúde. Revista Digital de Biblioteconomia e Ciência da Informação, Campinas, v. 2, n. 2, p. 1-17, 2005. Disponível em: <http://www.sbu.unicamp.br/seer/ojs/index.php/rbci/article/view/305>. Acesso em: 21 jan. 2012.

FELÍCIO, J. C. S. M. Serviço de Referência Educativo (SRE) em bibliotecas universitárias: análise das práticas voltadas ao desenvolvimento da competência em informação de usuários. Florianópolis, 2014. $222 \mathrm{f}$. Dissertação (Mestrado em Ciência da Informação) - Programa de PósGraduação em Ciência da Informação, do Departamento de Ciência da 
Informação, Florianópolis, 2014. Disponível em: <http://tede.ufsc.br/teses/PCIN0106-D.pdf > . Acesso em: 28 ago. 2014.

MACIEL, A. C., MENDONÇA, M. A. R. A função gerencial na biblioteca universitária. In: SEMINÁRIO NACIONAL DE BIBLIOTECAS UNIVERSITÁRIAS, 11., 2000. Florianópolis, Santa Catarina, SNBU 2000. Anais... 2000. Disponível em: <http://snbu.bvs.br/snbu2000/parallel.html>. Acesso em: 28 ago. 2014.

MATTOS FILHA, M. H. F. A biblioteca universitária e a educação superior a distância: estudo do planejamento dos serviços, compartilhamento da informação e do conhecimento nas universidades no Estado do Rio de Janeiro. Niterói, 2013. 219f. Dissertação (Mestrado em Ciência da Informação) - Universidade Federal Fluminense, Niterói, 2013. Disponível em:

<http://www.ci.uff.br/ppgci/arquivos/Dissert/2013/MARA\%20HELENA\%20FORNY\%2 0MATTOS\%20FILHA.pdf> Acesso em: 15 dez. 2013.

MATTOS FILHA, M. H. F.; CIANCONI, R. de B. Bibliotecas na educação a distância: caso do Consórcio CEDERJ. Inf. \& Soc.: Est., João Pessoa, v. 20, n. 1 , p. 129-138, jan./abr. 2010. Disponível em: <http://www.ies.ufpb.br/ojs/index.php/ies/article/view/4037/3425>. Acesso em: 28 ago. 2014.

MUELLER, S. P. M. Universidade e informação: a biblioteca universitária e os programas de educação à distância: uma questão ainda não resolvida. Datagramazero, Rio de Janeiro, v. 1, n. 4, p.1-11, ago. 2000. Disponível em: <http://www.dgz.org.br/ago00/Art 01.htm>. Acesso em: 25 fev. 2013.

NOVA, C.; ALVES,L. Educação a distância: limites e possibilidades. In: NOVA, C.; ALVES,L. Educação à distância: uma nova concepção de aprendizado e interatividade. São Paulo: Futura, 2003. p. 5-27.

PIZZANI, L. et al. A. A educação à distância e o treinamento de usuários de bibliotecas universitárias: a percepção dos acadêmicos. Revista Brasileira de Biblioteconomia e Documentação, São Paulo, v. 7, n. 2, p. 156-171, jul./dez. 2011. Disponível em: <http://rbbd.febab.org.br/rbbd/article/view/160/206 >. Acesso em: 11 jun. 2012.

RAMOS, P. B. A gestão na organização de unidades de informação. Ciência da Informação, Brasília, v. 25, n. 1, p. 1-11, 1996. Disponível em: $<$ http://revista.ibict.br/ciinf/index.php/ciinf/article/viewArticle/483 >. Acesso em: 11 jun. 2012.

SEMBAY, M. J. Educação a distância: bibliotecas de polos de apoio presencial e bibliotecários. Florianópolis, 2009. 173f. Dissertação (Mestrado em Ciência da Informação) - Universidade Federal de Santa 
Catarina, Florianópolis, 2009. Disponível em: <http://www.tede.ufsc.br/teses/PCIN0051-D.pdf >. Acesso em: 20 mar. 2013.

SENA, P. M. B.; TREVISOL NETO, O; VARVAKIS, G. Gestor e usuários: duas visões da proposta de valor de um centro de informação. Revista $A C B$, Florianópolis, v. 18, n. 2, p. 979-1000, jul./dez. 2013. Disponível em: <http://www.revista.acbsc.org.br/racb/article/view/911>. Acesso em: 30 out. 2013.

SOUSA, E. C. B. M. Panorama internacional da educação a distância. Em Aberto, Brasília, v. 16, n. 70, abr./jun. 1996. Disponível em: $<$ http://cabiouel.files.wordpress.com/2010/04/revista-em-aberto-educao-adistancia.pdf>. Acesso em: 19 mar. 2009. 